\title{
Short Term Outcome and Predictors of Mortality Among Very Low Birth Weight Infants-A Descriptive Study: Correspondence
}

\author{
Chetan Khare $^{1} \mathbb{D} \cdot$ Manish Jain ${ }^{1}$
}

Received: 6 July 2021 / Accepted: 16 July 2021 / Published online: 3 August 2021

(c) Dr. K C Chaudhuri Foundation 2021

To the Editor: We accolade the authors for their study on very-low-birth-weight (VLBW) mortality from tertiary care Indian setup [1]. However, a few concerns for the present study are summarized. Firstly, nearly $18 \%$ neonates of the enrolled neonates were treated with surfactant replacement therapy (SRT) for respiratory distress syndrome (RDS) and $60 \%$ of the SRT-treated RDS neonates were associated with mortality [1]. The present study aptly points out the ailments which contribute to high fatality rates amongst VLBW neonates. The burden of RDS mortality in developing countries is significant. From a public health point of view, the authors have suggested monitoring RDS-specific mortality in developing countries and evaluate causes of higher case fatality associated with RDS [2]. In line with these, monitoring the cause-specific neonatal mortality (e.g., RDS in preterm neonates) is one of the dashboard indicators of India Newborn Action Plan [3]. Since the present study enrolled only the inborn neonates, a physician-certified cause of deaths could have provided valuable data. Secondly, the study cohort's fatality rate of the VLBW neonates is lower than published literature; an overall care improvement in India is possibly the most important reason [4]. It has been speculated that nearly $95 \%$ of the neonates with RDS can be managed with combined use of continuous positive airway pressure (CPAP), SRT, and invasive ventilation [2]. However, bridging the huge gap in neonatal survival with RDS between developing and developed nations remains a challenge. From an intensivist point of view, the literature suggests an improved diagnosis of persistent pulmonary hypertension of newborn (PPHN) in preterm neonates in the present era [5]. We believe PPHN is under-reported in the study and is possibly a hidden culprit contributing to higher fatality rates.

Chetan Khare

drchetankhare@gmail.com

1 Department of Pediatrics, Mahatma Gandhi

Institute of Medical Sciences, Sevagram, Wardha,

Maharashtra 442102, India

\section{Declarations}

Conflict of Interest None.

\section{References}

1. Gupta S, Adhisivam B, Bhat BV, Plakkal N, Amala R. Short term outcome and predictors of mortality among very low birth weight infants-a descriptive study. Indian J Pediatr. 2021;88:351-7.

2. Kamath BD, Macguire ER, McClure EM, Goldenberg RL, Jobe $\mathrm{AH}$. Neonatal mortality from respiratory distress syndrome: lessons for low-resource countries. Pediatrics. 2011;127:1139-46.

3. India Newborn Action Plan (INAP) National Health Mission. In: MOHFW, GOI Publication. 2014. Available at: https://nhm.gov. in/images/pdf/programmes/inap-final.pdf. Accessed on 1 July 2021.

4. Ramanathan R, Bhatia JJ, Sekar K, Ernst FR. Mortality in preterm infants with respiratory distress syndrome treated with poractant alfa, calfactant or beractant: a retrospective study. J Perinatol. 2013;33:119-25.

5. Nakanishi H, Suenaga H, Uchiyama A, Kusuda S; Neonatal Research Network, Japan. Persistent pulmonary hypertension of the newborn in extremely preterm infants: a Japanese cohort study. Arch Dis Child Fetal Neonatal Ed. 2018;103:F554-F61.

Publisher's Note Springer Nature remains neutral with regard to jurisdictional claims in published maps and institutional affiliations. 